\title{
Prevalence of Chronic Otitis Media among Undernourished Children
}

\author{
Shehanaaz Shajahan ${ }^{1}$ Rajeshwary Aroor ${ }^{2}$ \\ ${ }^{1}$ K.S. Hegde Medical Academy, Mangalore, Karnataka, India \\ ${ }^{2}$ Department of ENT, K.S. Hegde Medical Academy, Mangalore, \\ Karnataka, India
}

\begin{abstract}
Address for correspondence Rajeshwary Aroor, MBBS, MS, Department of ENT, K.S. Hegde Medical Academy, Mangalore 575018, Karnataka, India (e-mail: rajeshwarisomayaji@gmail.com).
\end{abstract}

J Health Allied Sci NU 2020;10:27-30

\begin{abstract}
Keywords

- chronic suppurative otitis media

- undernourished children

- prevalence

Objective This study aimed to identify the role of nutrition in the etiology of chronic suppurative otitis media (CSOM) by comparing the prevalence of CSOM between undernourished children with normal children aged between 10 and 12 years.

Materials and Methods A total of 200 children aged between 10 and 12 years studying in government schools were selected for the study. All the children underwent a general and detailed ENT examination in addition to nutritional assessment based on body mass index calculation, using World Health Organization (WHO) Child Growth Standards Chart. The children were divided into two groups: Group A and Group B. Group A consisted of 100 children who were malnourished and Group B consisted of 100 children who were normal. The presence of CSOM in the two groups was noted.

Results and Observations Of the total 200 children, 112 were boys (56\%) and 88 were girls (44\%). Of the 112 boys, 22 (19.64\%) had CSOM and out of 88 girls, 24 (27.27\%) had CSOM. Of the total 46 children found to have CSOM, 35 children (76.1\%) belonged to Group A and 11 children (23.9\%) belonged to Group B.

Conclusion Our study shows that there is a higher prevalence of CSOM among undernourished children than in normal children. High prevalence of CSOM in undernourished children is a preventable health problem that needs health education and active intervention.
\end{abstract}

\section{Introduction}

Chronic suppurative otitis media (CSOM) is a condition characterized by recurrent or persistent ear discharge (otorrhea) through a perforation in the tympanic membrane. ${ }^{1}$ It is one of the most common ear diseases in developing countries. ${ }^{2}$ It is the most common cause of persistent mild-to-moderate hearing impairment in children and young adults. ${ }^{3}$

The etiology and pathogenesis of CSOM are multifactorial that include genetic, infections, allergy, environmental, social and racial factors, and Eustachian tube dysfunctions. ${ }^{4}$ High rates of CSOM in developing countries have been attributed to overcrowding, inadequate housing, poor nutrition, passive smoking, high rates of nasopharyngeal colonization with potentially pathogenic bacteria and inadequate or unavailable health care facilities. ${ }^{5}$
CSOM produces mild-to-moderate hearing loss in 50\% cases and is an important cause of preventable hearing loss in the developing world. Hence, it is important to increase awareness about this disease among the population so as to reduce the morbidity due to its complications.

The aim of this study is to compare the prevalence of CSOM among undernourished and normal children in the same region and to know the role of nutritional deficiencies in the etiology of CSOM. Not many studies have been conducted establishing the role of nutritional factors in the pathogenesis of CSOM.

\section{Materials and Methods}

This was a prospective cross-sectional study performed in school going children aged 10 to 12 years. A total of 200 
children from government schools were selected for the study as most of the children belonged to poor socioeconomic strata.

The study was conducted after obtaining necessary approvals from the institutional ethical committee and principals of the schools. An informed consent was also taken from the parents of these children

Following general examination and a detailed ENT examination, the children were categorized into two groups: Group A and Group B. Group A consisted of 100 children that were malnourished and Group B consisted of 100 children that were normal. Nutritional assessment of the children was decided based on body mass index (BMI) calculation, using World Health Organization (WHO) Child Growth Standards Chart. ${ }^{6}$

BMI is calculated as weight in $\mathrm{kg} / \mathrm{height}$ in $\mathrm{m}^{2}$.

BMI ranges between 15 th and 50 th percentile was considered normal. A BMI below the 15 th percentile was considered as malnourished and that above the 50th percentile was considered overweight. All children with a BMI less than 15th percentile were categorized as Group A and children with a BMI above 15th percentile to 50th percentile were categorized as Group B. The nutritional status was assessed based on anthropometric examination for which the following body measurements were used:

\section{Height \\ 2. Weight \\ 3. BMI}

The standard value of weight of children between 10 and 12 years of age was considered $34.3 \mathrm{~kg}$ for boys and $35 \mathrm{~kg}$ for girls. The standard value of height for boys of the same age group was 137 to $147 \mathrm{~cm}$ and 138 to $148 \mathrm{~cm}$ for girls.

The diagnosis of CSOM was made based on a history of ear discharge for more than 3 months and otoscopic examination demonstrating a central perforation in the pars tensa. Presence of associated nasal and pharyngeal ailments was ruled out. Information regarding family composition, socioeconomic status, and family history of ear disease was also obtained.

Children with cleft palate and other congenital diseases, associated pathologies like adenoiditis, tonsillitis, and allergy with nasal and throat symptoms and ear discharge due to other causes like squamosal type of CSOM were excluded from the study.

\section{Observations and Results}

Of the total 200 children, 112 were boys (56\%) and 88 were girls (44\%). Of 112 boys, 22 (19.64\%) were diagnosed with CSOM and of 88 girls, 24 (27.27\%) were diagnosed with CSOM (-Table 1). In our study, there was no significant difference in prevalence of CSOM between the two sexes.

Unilateral disease was observed in 44 out of 46 children (95.65\%) and 11 (23.9\%) were found to have active ear discharge. Of the total 46 children found to have CSOM, 35 children (76.1\%) belonged to Group A and 11 children (23.9\%) belonged to Group B.
All the children were selected for the study belonged to poor socioeconomic status with most parents being daily wagers. Out of the 200 children, 5 children gave a family history of ear disease. Only 12 children with CSOM belonged to large households.

\section{Discussion}

CSOM is one of the most common health problems in India and is more common among the rural community where there is a lack of adequate health facilities.

CSOM is of two types: tubotympanic type and atticoantral type. Tubotympanic type is now known as mucosal disease. Atticoantral type is now known as squamous disease. ${ }^{7}$ These terminologies are yet to be popularized. In this study, only tubotympanic type of disease was included. Tubotympanic type of CSOM is characterized by profuse and mucopurulent discharge, usually through a central tympanic membrane perforation, with hearing loss usually $\sim 30$ to $40 \mathrm{~dB}$.

The WHO has indicated that a prevalence rate of CSOM greater than $4 \%$ in a defined population of children is indicative of a massive health problem requiring urgent attention. According to a WHO report, global burden of illness from CSOM involves 65 to 330 million individuals with draining ears, $60 \%$ of whom suffer from significant hearing impairment. Over $90 \%$ of the burden is borne by the countries in the South East Asia (including India) and Western Pacific regions. ${ }^{8}$

According to a recent estimate from a school survey in Tamil Nadu, the prevalence rate of CSOM in India is 7.8\%, which is high but is lower than previous estimates that ranged from 16 to 34\%. In India, the overall prevalence rate is 46 per thousand individuals in rural population and 16 per thousand individuals in urban population. ${ }^{8}$

This study was undertaken among 200 children in the age group of 10 to 12 years, selected from a semi-urban center. In our study, the prevalence of CSOM among the children was found to be $23 \%$ ( 46 out of 200 children). A similar study conducted to determine the prevalence of CSOM among two groups of children living in slum areas of Dhaka city showed the prevalence of CSOM was $7.29 \%$ in 203 children. ${ }^{9}$ Another cross-sectional study conducted in Hooghly showed high prevalence of CSOM in rural students (20\%), when compared with urban students (12.6\%). ${ }^{10}$ Compared with all other studies, our study shows very high prevalence of CSOM among the school children. The reason for such high prevalence rates could be due to lack of adequate health care facilities and awareness among the parents. Since this disease is an important cause of preventable hearing loss among children, it is important to increase the awareness among the community and thus reduce its morbidity.

Poverty has been noted to be a major risk factor in developing countries and certain neglected populations. ${ }^{11}$ Swimming in polluted water is an important cause of otitis media among the children in India as it can cause infection in the middle ear resulting in acute suppurative otitis media. If these cases are left untreated, they may later develop into CSOM. Other causes for higher prevalence of CSOM in developing countries 
Table 1 Distribution of CSOM among boys and girls

\begin{tabular}{|l|l|l|l|l|}
\hline Sex & Number of children & $\begin{array}{l}\text { Number of children } \\
\text { having CSOM }\end{array}$ & $\begin{array}{l}\text { Number of children } \\
\text { having CSOM in Group A }\end{array}$ & $\begin{array}{l}\text { Number of children } \\
\text { having CSOM in Group B }\end{array}$ \\
\hline Boys & $112(56 \%)$ & $22(19.64 \%)$ & 17 & 5 \\
\hline Girls & $88(44 \%)$ & $24(27.27 \%)$ & 18 & 6 \\
\hline Total & $200(100 \%)$ & $46(23 \%)$ & 35 & 11 \\
\hline
\end{tabular}

Abbreviation: CSOM, chronic suppurative otitis media.

are poor hygiene, poor living conditions, overcrowding, and poor nutrition. ${ }^{12}$ Okafor found that the majority of the patients with chronic ear disease came from communities living in agricultural or slum areas of the cities. ${ }^{1}$

Our study shows higher prevalence of CSOM in undernourished $(76.1 \%)$ compared with normal children (23.9\%). This indicates the possible role of nutritional deficiencies in the etiology of CSOM. Studies have shown that children with CSOM were more undernourished than controls, with lower mean serum zinc, selenium, and calcium concentrations. Vitamin D-deficient and iron-replete children had a longer duration of infection. ${ }^{13}$ Children with deficiencies of vitamin A and zinc were found to be more prone to middle ear pathologies. ${ }^{14}$ However, in our study even the normal children showed a high prevalence of CSOM; this may be due to deficiency of these micronutrients.

The main cause for poor nutrition among these children is poverty. In this study, 100 children were malnourished, that is, based on BMI calculation, their BMI was less than 15th percentile for that age. Parents of most of these children were daily wagers with low income that is distributed over a large household. This could be the cause of poor nutrition of both micro-and macronutrients among these children thus predisposing them to infectious diseases including CSOM. Supplementation of Vitamin A and D along with micronutrients in the mid-day meal may reduce the prevalence of CSOM in these children.

In this study, only government schools were selected so that all the children would belong to the same socioeconomic strata. Uddin et al conducted a study in Pakistan, which showed a higher prevalence of CSOM in children from government schools compared with children from private schools. ${ }^{15}$ The could be due to differences in the socioeconomic status between the two populations and lower educational status noted among parents of children in the lower socioeconomic group attending government schools.

Studies have also shown overcrowding or large family size as a risk factor for CSOM. ${ }^{12}$ In our study, 44 children were found to be belonging to large households ( $>8$ members). Out of these 44 children, 12 children were found to have CSOM. Increased number of children in a household can lead to overcrowding that is a significant risk factor for CSOM. Poor housing and overcrowding predispose to recurrent upper respiratory tract infections, thereby contributing to chronic middle ear infection.

It has been observed that several government schools are closing down in recent years due to poor enrolment that could indicate an improvement in socioeconomical status of the population. Parents prefer private school education for their children over resource-poor schools run by the government. Hence, only children from extremely poor socio-economic groups are enrolled at government schools. This could be the reason for the higher prevalence rate of CSOM noted in our study

Hearing loss is an important sequel of CSOM with functional implications on the quality of life. The level of hearing loss may be up to $40 \mathrm{~dB}$ and can cause impairment in the development of speech and cognitive abilities, thereby reducing the academic performance of children. ${ }^{16}$ Rao and Jayakar conducted a study that showed CSOM to be the single major cause for hearing loss in $66.3 \%$ cases. ${ }^{17}$ Reduced academic performance caused by CSOM can be one of the causes for widening the economic gap between the rich and the poor.

\section{Conclusion}

The results of our study show that there is a higher prevalence of CSOM among undernourished children than in normal children. This suggests that nutritional deficiencies may be a risk factor for CSOM. High prevalence of CSOM in our study should be considered as serious health problem and urgent intervention is required. CSOM is the commonest cause of preventable hearing loss in children; hence, it is necessary to combat this disease as early as possible. Efforts should be made to improve the socioeconomic status and the health care facilities available to the community.

\section{Ethical Approval}

This article does not contain any studies with animals performed by any of the authors. Ethical approval from institutional review board was taken.

\section{Note}

This is short-term ICMR student research project.

\section{Conflict of Interest}

None declared.

\section{References}

1 Okafor BC. The chronic discharging ear in Nigeria. J Laryngol Otol 1984;98(2):113-119

2 Batia PL, Varughese R. Pattern of otorhinolaryngological diseases in Jos community. Niger Med J 1987;17:67-73

3 Teele DW, Klein JO, Rosner BA. Epidemiology of otitis media in children. Ann Otol Rhinol Laryngol Suppl 1980;89(3 Pt 2) :5-6

4 Maharjan M, Bhandari S, Singh I, Mishra SC. Prevalence of otitis media in school going children in Eastern Nepal. Kathmandu Univ Med J (KUMJ) 2006;4(4):479-482 
5 Lasisi AO, Olaniyan FA, Muibi SA, et al. Clinical and demographic risk factors associated with chronic suppurative otitis media. Int J Pediatr Otorhinolaryngol 2007;71(10):1549-1554

6 WHO. The WHO Child Growth Standards. Available at: https:// www.who.int/childgrowth/standards/en/. Accessed April 27, 2020

7 Browning GG, Justine W, Kelly G, Swan RC, Scott-Browns Otolaryngology and Otology, 8th edition. London: CRC Press; 2018:977-994

8 Jose Acuin. World Health Organization. Chronic Suppurative Otitis Media. Burden of Illness and Management Options. 2004. Available at: https://apps.who.int/iris/handle/10665/42941. Accessed April 4, 2020

9 Kamal N, Joarder AH, Chowdhury AA, Khan AW. Prevalence of chronic suppurative otitis media among the children living in two selected slums of Dhaka City. Bangladesh Med Res Counc Bull 2004;30(3):95-104

10 Bandyopadhyay R, Sengupta A, Dasgupta A, Biswas R, Mukherjee S, Biswas AB. A comparative study of common ear morbidity pattern among the primary school children of an urban slum of Kolkata and rural area of Hooghly. J Indian Med Assoc 2005;103(8):428-432, 430-432
11 Yaor MA. Care of the discharging ear in children. Afr Health 1999;21(6):15

12 Lasisi AO, Olayemi O, Irabor AE. Early onset otitis media: risk factors and effects on the outcome of chronic suppurative otitis media. Eur Arch Otorhinolaryngol 2008;265(7):765-768

13 Elemraid MA, Mackenzie IJ, Fraser WD, Brabin BJ. Nutritional factors in the pathogenesis of ear disease in children: a systematic review. Ann Trop Paediatr 2009;29(2):85-99

14 Elemraid MA, Mackenzie IJ, Fraser WD, et al. A case-control study of nutritional factors associated with chronic suppurative otitis media in Yemeni children. Eur J Clin Nutr 2011;65(8):895-902

15 Uddin W, Hussain A, Khan A, et al. Prevalence and comparison of chronic suppurative otitis media in government and private schools. Ann Pak Inst Med Sci 2009;5(3):141-144

16 Olatoke F, Olage FE, Nwawolo CC, Saka MJ. The prevalence of hearing loss among school children with chronic suppurative otitis media in Nigeria and its effect on academic performance. Eur J Clin Nutr 2011;65(8):895-902

17 Rao MV, Jayakar PA. Bacteriological study of chronic suppurative otitis media. J Indian Med Assoc 1980;75(2):30-34 